\title{
Risk communication and risk perception: lessons from the 2011 floods in Brisbane, Australia
}

Mark Kammerbauer Associate, Augsburg University of Applied Sciences, Germany and John Minnery Adjunct Professor, Cities Research Institute, Griffith University, Australia

Risk communication and risk perception are critical factors in disaster management. Governments at all levels play a part in communicating risk, whereas the perception of risk entails active roles by community participants, including potential and actual victims of disasters. This paper discusses these matters in relation to the floods in Brisbane, Australia, in 2011. The findings are based on interviews with representatives of households whose dwellings or business premises were fully or partially inundated by the waters. The research shows how important it is to recognise the problems of institutional fragmentation in terms of communication and the active engagement of recipients in understanding and interpreting flood risk information (especially for slow-onset riverine flooding, such as that suffered by Brisbane). Locally targeted information on risk is of vital importance in avoiding the misinterpretation of warning information in relation to environmental cues and in promoting adequate responses. The paper concludes with some relevant recommendations.

Keywords: Brisbane, disaster response, floods, risk communication, risk perception

\section{Introduction}

Natural hazards and resulting disasters affect cities around the globe. As the world urbanises, the increased concentration of buildings, infrastructure, and people intensifies the ramifications of disasters. One type of major environmental disaster is flooding, and many Australian cities, located as they are on rivers and in a land of 'drought and flooding rains' (Mackellar, 1908), are impacted by such events. Governments at all levels have invested significant effort in understanding, communicating, and managing flood-related risks.

This paper seeks to explore ideas concerning risk communication and risk perception using the experiences of households whose business premises or dwellings were inundated during the 
major flooding that occurred in Brisbane, Australia, between December 2010 and January 2011. ${ }^{1}$ As will be shown, perceptions of risk are influenced by environmental, psychological, social, and technological factors, some of which appear to be only partially integrated into local disaster management systems.

This research seeks to answer two questions:

1. What can the experiences of flood-affected community residents tell us about risk communication and risk perception?

2. What lessons can research and policy on flood risk communication and risk perception draw from the experiences of Brisbane in 2011?

Although it is common in the literature and in practice to conceptualise disaster issues via a cycle made up of a series of stages - prevention-preparedness-(disaster)-response-recovery (PPRR) (see Emergency Management Australia, 2004, pp. 4-5) - this research points to considerable overlap between them. While it focuses on the disaster and response phases of the Brisbane floods, actions and impacts were shaped to a large extent by the period before the unfolding disaster when risk communication and risk perception were paramount. The research also provides lessons for the prevention and preparedness phases of the next disaster management cycle.

After this introduction the concepts of risk communication, risk perception, and warning in relation to disaster management (especially in the context of riverine floods) are discussed and their importance for this research is outlined. The third section provides the specific context for the 2011 flood in Brisbane. The fourth section explains the research methods used, and the fifth section provides empirical data on risk communication, risk perception, and relevant overlaps and gaps between the two. The final section seeks to answer the research questions through discussion, and offers some conclusions and recommendations.

1 The flood began in December 2010, but peaked in early January 2011. It is referred to in this paper, therefore, as the 2011 flood. 


\section{Risk communication, risk perception, and warning}

Risk communication and risk perception are central to disaster planning and management, but, as will be shown, both are increasingly being recognised as complex phenomena. Most commonly, risk communication is seen as a process initiated by government or other official agencies, the purpose of which is to enable a community to respond appropriately, but actual perception of risk may lead to varying results, and in fact to results that are not intended (Wildavsky and Dake, 1990; Rahm and Reddick, 2011; Twigg, 2013). In the context of natural hazards, it is crucial that accurate and reliable information on risk is made available and conveyed to those who require it. Yet, it is also critical that the information is meaningful to and understood by those receiving it. The purpose of such risk communication is to help actors from civil society and the government to respond appropriately. Different actors understand hazard and disaster risk differently, and there may be considerable disparity between those explaining the risk and those for whom the explanation is intended, such as emergency planners, engineers, land developers, local governments, and residents (Green, Tunstall, and Fordham, 1991; Godber, 2005b). Hence, the communication of risk is considered to be 'a complex area of study and practice [. . .] where risk perception, attitude and behaviour can be attenuated or amplified by a range of cognitive, social, cultural and institutional factors' (Shepherd and van Vuuren, 2014, p. 471).

Risk communication and risk perception can be better understood in the context of warning as an overarching field of activity and research. Warning is characterised by interrelated psychological and sociological dimensions and is described as a process that is produced by social organisation (Perry, 1979, p. 441; Dash and Gladwin, 2007, p. 69). Warning systems are defined as the first of the key elements of warning, and comprise the 'means of getting information about an impending emergency, communicating that information to those who need it, and facilitating good decisions and timely response by people in danger' (Mileti and Sorensen, 1990, pp. 1-20). Basic models of such systems include subsystems that cover the functions of detection, communication, and response. A warning is supposed to describe a hazard, indicate the possible time and extent of the impact, and suggest appropriate adaptation measures. An optimal warning refers to adaptive measures that are communicated beforehand and that can be carried out based on the information given (Perry, 1979, pp. 441-444). It needs to be heard, understood, believed, and personalised; and it should prompt a response (Mileti and Sorensen, 1990, pp. 5-10). 


\section{Risk communication}

The purpose of an emergency warning system as a tool for disaster response is the communication of information on risks. Individuals at risk need to be alerted about a disaster threat; those not at risk also need to be informed in order to confirm their own safety. Warnings can come from longer-term residents, relatives, social media, or even through house-to-house sharing of information (Mileti and Sorensen, 1990). One of the factors identified as having a substantial influence is previous experience (Elrick-Barr et al., 2015). If individuals have already suffered losses owing to a disaster, they are more likely to respond to warning messages (Mileti and O'Brien, 1992, p. 53).

Effective information on risk should answer the following questions: what is the specific hazard? What should individuals do? How much time is left before impact? Is the information communicated frequently across multiple channels? Are the sources official? Can the information be confirmed? (Mileti and O'Brien, 1992, p. 42). Typically, local government actors decide whether or not a warning needs to be issued (Mileti and Sorensen, 1990, pp. 2-3) and confidence in the local government tier tends to be greater than that in higher levels of government (Kim and Oh, 2015, p. 115). If certain parameters are met, an alert can be triggered and related information can be communicated. The way in which the involved subsystems interact is vital, including when 'scientists communicate to officials in emergency management' (Mileti and Sorensen, 1990, p. 2-1).

There are, in fact, ways of modelling flood risk communication. A useful approach is that of Demeritt and Norbert (2014), who, following Wardman (2008), describe four models mapped on a vertical axis showing the underlying rationale of communication (from normative to instrumental) and a horizontal axis showing engaged, two-way communication at one extreme and less engaged, one-way communication at the other. The model illustrated in each quadrant is described as an 'ideal type'. Thus, when communicating information on risks, the roles of those involved, the governmental institutions as well as those conventionally seen as the recipients, need to be considered (Rodriguez et al., 2007; Twigg, 2013). In addition, though, the underlying assumptions behind the communication are important. There is an expectation (often legally 
mandated) that the government agencies that are responsible for emergency and disaster planning are required to communicate risks to the public, but they are not the only ones from whom the public acquires such information. Generalised warning information can be derived during the prevention and preparation phases of the disaster cycle (using flood maps when purchasing a property, for instance) and these can have an effect on the efficacy of the warnings issued for a specific disaster (Mileti and Sorensen, 1990, p. 2-2). For intended recipients, the information supplied should be: comprehensible and useful; relevant and correspond to actual needs (which requires making recipients aware of risk and possible impacts); and related to capacities available and resources required to deal with a disaster. The timeliness of the information is also important to enable necessary preparation and action. Communication involves more than just making information available. Burningham, Fielding, and Rush (2008, p. 217) highlight that the official approach of the United Kingdom's Environment Agency to communicating flood risk uses an implicit 'deficit model' that assumes that 'people lack accurate information and if this were to be provided their awareness deficit would be met'. The 'deficit model' also assumes that once all people have been made conscious of the risk, they will all have a similar understanding of potential disaster outcomes, but this is not always the case.

\section{Risk perception}

Both group cultural/social processes and individual psychological processes are seen as the reason for different individual perceptions of risk. They can lead to different results and responses when a warning message is heard (Mileti and Sorensen, 1990). When individuals receive warnings, their risk perception is shaped by different, sequential stages, which some researchers characterise as 'hear-confirm-understand-believe-personalise-respond' (Mileti and O’Brien, 1992, p. 41), although Kellens, Terpstra, and De Maeyer (2013) identify a range of paradigms that inform research on risk perception, grounded in different theoretical assumptions about psychometrics, heuristics, and behaviour. Based on the warning provided by the management subsystem, the information people receive is subject to interpretation: 'even though everyone may be listening to the same warning information message, different people can reach different conclusion[s] about what they hear' (Mileti and Sorensen, 1990, p. 2-10). While risk is understood in terms of probability and consequences, risk perception is seen to 'include social dimensions based on the decision-maker's frames of reference' (Dash and Gladwin, 2007, p. 70), 
or what Drabek (2005, p. 51) calls 'multiple layers of social constraint'. From this point of view, theories of risk perception enrich theories on risk communication by offering a better understanding of how individuals respond to warnings, since warning information is 'processed within social contexts that influence how individuals assess the level of danger' (Dash and Gladwin, 2007, p. 71). Bubek, Botzen, and Aerts (2012, p. 1483) note that 'perceived risk' or level of danger "refers to the combined measurement of "perceived probability" and "perceived consequences" of a certain event or activity'. Their systematic literature review shows that this 'perceived risk' is but one of the factors influencing the adoption of private flood mitigation measures. Similarly, factors other than perceived risk influence how individuals respond to flood warnings, including those that refer to their cultural and psychological context.

Douglas and Wildavsky (1982, p. 30) emphasise this understanding by stating that 'what human beings perceive as threats to their wellbeing and how they evaluate probabilities and magnitudes of unwanted consequences, are less a question of predicted physical outcomes than of values, attitudes, social influences and cultural identity'. Mileti and Peek (2000, pp. 181-182) express this as the need 'to understand the fundamental processes whereby people define reality in order to understand how they respond to warnings since they act on these definitions in attempting to create their own desired reality'. Risk perception can also vary according to the role of the stakeholder involved. For example, the study by Godber (2005a, 2005b) demonstrated that perception of risk, particularly in terms of what was felt to be 'acceptable risk' of flooding, differed among emergency managers, land developers, local governments, and residents in relation to a defined floodplain on the Gold Coast of Australia. It also differed among many of the members of each category. The assumptions underpinning the way that risks are perceived and then framed can have a major bearing on the way in which they are understood by recipients (Henrich, McClure, and Crozier, 2015). ${ }^{2}$

\section{Warning}

$\underline{\text { Response }}$

2 Recipients of information on risk also assume active roles relating to choosing particular sources of information and interpretation of this information based on 'unique experiences and perceptions on hazards and disasters' (Rodriguez et al., 2007, p. 481). 
The specific adaptive measures or responses that are proposed to the population within the actual warning are key elements of the warning system (Perry, 1979). In addition, they must be viewed as both psychological and social processes (Mileti and O’Brien, 1992). When governmental institutions warn individuals that evacuation is necessary owing to a hazard, different responses can be the outcome, based on how individuals evaluate a risk and the related response options (Dash and Gladwin, 2007, p. 70). Pre-impact evacuation is an appropriate adaptive measure in the event of riverine floods. To ensure a successful evacuation, safe locations and shelters need to be identified, routes mapped, and means of transport provided for those without access to a personal vehicle or who do not have the capacity to secure transportation on their own. A lack of knowledge of routes and destinations for evacuating can limit compliance with the warning. For families, evacuating together, and, even more significantly, receiving information on the location of family members, are considered to be effective incentives for evacuation, as well as the (symbolic) protection of property (Perry, 1979, pp. 443-445). Problems arise when information is incorrect or too complex to understand, such as 'where forecasters, emergency managers, and the public have very different levels of expertise and understanding of scales and diagrams representing [...] risk' (Dash and Gladwin, 2007, p. 75).

\section{$\underline{\text { Cues }}$}

When information on risk is communicated, the response that follows can be categorised according to environmental, psychological, and social attributes (Mileti and O'Brien, 1992, p. 42; cf. Mileti and Sorensen, 1990, p. 5-5). ${ }^{3}$ These attributes relate to certain cues that can influence evacuation behaviour (Dash and Gladwin, 2007, p. 70). Environmental attributes sum together 'those cues which either do or do not support the warning information that has been received' (Mileti and Sorensen, 1990, p. 5-6), including physical and social indicators and proximity in terms of distance or time. The actual weather plays a role and can influence whether or not individuals choose to comply with warnings: as Mileti and Sorensen (1990, p. 2-2) note, 'it can be difficult to issue flood warnings on a sunny day'. Social cues include situations where 'neighbors are seen evacuating when evacuation warnings are received' (Mileti and Sorensen, 1990, p. 5-6). As an extension of the environment, the 'physical characteristics of residences are

Also categorised as ‘a series of perceptions' (Mileti and O’Brien, 1992, p. 41) or 'dimensions' (Dash and Gladwin, 2007, p. 70). 
also important' (Kim and Oh, 2015, p. 113). This has salience in Brisbane where many houses are 'high set' (that is, they are raised some metres above ground level on concrete, steel, or wooden stumps) - many of the houses in flood-affected areas are high set as a flood mitigation measure. Psychological attributes encompass knowledge of a particular hazard and related plans and actions, whereas social attributes include economic, physical, and social resources. A problem materialises when a disconnection exists between the warning and these cues. If a cue does not result in action on the part of an individual at risk, this indicates either the absence of experience or knowledge of disasters, a lack of social networks, or 'fatalistic cognitions' (Mileti and Sorensen, 1990, p. 5-7). ${ }^{4}$

\section{Confirmation}

Typically, individuals react to warnings by seeking additional information or a confirmation. This is facilitated by communication with others or by repeatedly broadcasting the warning (Mileti and Sorensen, 1990, p. 5-12). Research also shows that 'people who fail to confirm a message tend not to evacuate' (Perry, 1979, p. 444). Confirmation of a warning can include various environment-related aspects, such as seeing "if the weather "looks" like a flood is coming' (Perry, 1979, p. 444). Paying attention to how neighbours behave and communicating with family and friends also serve to confirm warnings. An official telephone number that can be rung after a warning has been issued can help to confirm the warning itself and provide callers with important information (Perry, 1979). The perception of individuals can lead to confirmation, as it is informed by their social environment, but also it can lead to alterations of the warning message (Mileti and Sorensen, 1990, p. 2-2). Warning confirmation centres are viewed as a possible solution to the need to confirm warnings; they can also help to keep rumours under control. The creation of such centres is related to technological innovation. Equally important is official designation of such a centre 'as the community's source of emergency information' (Perry, 1979, p. 445). The public needs to be aware of this official designation, since the credibility of the source of the warning is crucial. ${ }^{5}$

\footnotetext{
$4 \quad$ Research also points out that cues that do not support a warning response 'can be overcome through planning' (Mileti and Sorensen, 1990, p. 2-2).

$5 \quad$ Particular risks about which governmental institutions may aim to inform and educate the public may be offset by benefits that motivate people to accept or tolerate them (Twigg, 2013, p. 177). This underscores that awareness needs to be
} 
Since risk perceptions may vary, responses may differ as well. When these complex ideas of risk perception and communication are married, there is room for unintended consequences to arise. Theories about warning systems can identify key points that offer a better understanding of these ramifications. For the purpose of this study, the following key points served to guide the empirical research:

- warning systems require careful planning and design to communicate information on risks;

- perceptions of risk can limit compliance with and the response to information on risks communicated by warnings;

- compliance with warnings can be improved by incentives, such as (symbolic) protection of property, and correct and comprehensible information;

- environmental cues are important for citizens to respond to warnings, including weather conditions, flood patterns, and the physical properties of dwellings, such as related mitigatory measures; and

- confirmation of warnings by official confirmation centres or technological innovations can support compliance with and the response to warnings.

Lindell and Perry (2012) integrate these various factors into their 'protective action decision model'. Although this model is not used here, because the focus is on risk, warnings, and communication, rather than on subsequent actions, it is interesting to note that it does include environmental and social cues, information sources, channel access and preferences, warning messages, and receiver characteristics, which affect 'pre-decision processes', leading, inter alia, to 'threat perception' (Lindell and Perry, 2012, p. 617). These many factors influence risk perception.

created in both directions of this communication process. Recipients among the public and affected communities should be considered, therefore, as 'active components [. . .] and not passive bystanders' (Rodriguez et al., 2007, p. 481). Consequently, researchers call for a departure 'from the traditional supply-driven model' towards models oriented to demand and 'in relation to their own circumstances and understandings of risk' (Twigg, 2013, p. 177). 
Yet, disconnections between risk communication and risk perception, between the information given and actual environmental circumstances, and between those who issue the warning and those for whom warnings are intended can limit compliance with and the response to a warning. This paper explores these issues as reported by victims of the 2011 floods in Brisbane.

\section{The 2011 floods in Brisbane}

Much of Brisbane, the capital of the state of Queensland in Australia, is located on a floodplain. The city is also situated in the subtropics and thus is subject to heavy and intense rainfall that occurs on the fringes of cyclones or as cyclones moving southwards collapse into rain depressions. Since the first formal settlements by Europeans in 1824, Brisbane has confronted several severe floods - the most widely known are those that occurred in 1890, 1893, 1908, 1931, 1974 and 2011.

The 2011 floods are the focus of this paper. The impact was enormous in Brisbane and across Queensland: '[m]ore than 78 per cent of the state of Queensland was declared a disaster zone an area bigger than France and Germany combined - with the floods affecting 2.5 million people, and causing 33 deaths. In the state capital Brisbane and the nearby city of Ipswich, flooding affected 22,000 properties and 7,600 businesses' (Shepherd and van Vuuren, 2014, p. 469). These authors explain that there had been continuous rainfall across most of eastern Queensland during the last few months of 2010. In the region of southeast Queensland, where Brisbane is found, river catchments were already saturated from the spring (September to November) rain.

Most of eastern Queensland received heavy rainfall during December 2010 and into January 2011, but there was a period of intense rainfall in the Brisbane River catchment from 9-13 January 2011, associated with the decaying Tropical Cyclone Tasha. Much of this rainfall was upstream from Brisbane's two major water storage facilities: the Somerset Dam and the Wivenhoe Dam. The Brisbane River flooded as a result of this rainfall, peaking at 4.46 metres at the Brisbane City Gauge on 13 January 2011 (Australian Government, Bureau of Meteorology, 
2011). While this paper concentrates on flooding in Brisbane, it is important to note that almost three-quarters of local governments across Queensland were affected by flooding; some more than once. Clearly, this had an impact on the Government of Queensland's communication and disaster management resources.

The role of the management of the Wivenhoe Dam was controversial in terms of its impact on Brisbane because, according to some commentators, the January 2011 event was at least partially a 'dam release' flood (Insurance Council of Australia, 2011, p. iv). However, management of the dam during the floods is the subject of ongoing legal action and thus is not considered in detail here. The presence of the Wivenhoe Dam and its potential for flood management did affect community perceptions of flood risk, so where interview responses refer to them they are included.

The 2011 floods also need to be set in the context of previous floods in Brisbane, especially the events of January 1974, when the river peaked at 5.45 metres at the City Gauge, just one metre higher than in 2011. Many Brisbane residents know about the 1974 floods and many of the people interviewed for this research mentioned it - some had even been affected in 1974 and 2011. The 1974 floods were the trigger for the construction of the Wivenhoe Dam, completed in 1984. The dam, though, highlights the competing purposes of such infrastructure, in this case flood mitigation, recreation, and the supply of water (Seqwater, 2015a, 2015b). The potentially conflicting purposes of the dam remain a matter of contention and were part of the brief of the Queensland Floods Commission of Inquiry (QFCI) (QFCI, 2011).

\section{Methods}

The data for this research were obtained from semi-structured interviews with household representatives that had experienced the 2011 floods in Brisbane. Three suburbs affected by the flooding were identified. They all had medium-to-high socioeconomic status: Graceville, with a population of 4,226 in 2011, was in the highest decile socioeconomic ranking of suburbs across the state; Sherwood, with a population of 5,005 in 2011, was also in the tenth decile; and Oxley, with a population of 7,301 in 2011, was in the eighth decile (Australian Bureau of Statistics, 2013). The interview topics were derived from an analysis of the literature on flood response and 
recovery. As experience of the floods was likely to have been traumatic for impacted households, the means of obtaining willing participants was a letterbox drop in flood-affected areas with an explanation of the research and its aims and an invitation to take part. Approximately 400 such invitations were delivered. As a result, 16 people contacted the researchers and were interviewed between late September and early November 2014-five were from Sherwood, six from Oxley, and five from Graceville (see Table 1). The interviewees are de-identified to maintain confidentiality. They were self-selected, so they do not represent the full population of affected households. Their experience of the 2011 floods ranged from total inundation of their house to partial inundation of the property and the lower part of the house. Most were present for the flood. One household was away on holiday during the disaster, but had returned afterwards for the clean-up and recovery. In addition, they were able to report on the observations of their family members who were housesitting during the flood.

Table 1. Interviews, suburbs, and dates

\begin{tabular}{|l|l|l|}
\hline $\begin{array}{l}\text { Interviewee } \\
\text { identification }\end{array}$ & Suburb & Date \\
\hline A & Sherwood & 2 October 2014 \\
\hline B & Oxley & 11 November 2014 \\
\hline C & Sherwood & 27 October 2014 \\
\hline D & Graceville & 16 October 2014 \\
\hline E & Oxley & 8 October 2014 \\
\hline F & Oxley & 8 October 2014 \\
\hline G & Oxley & 9 October 2014 \\
\hline H & Graceville & 9 October 2014 \\
\hline I & Oxley & 3 November 2014 \\
\hline J & Graceville & 13 October 2014 \\
\hline K & Sherwood & 2 October 2014 \\
\hline L & Graceville & 12 October 2014 \\
\hline
\end{tabular}




\begin{tabular}{|l|l|l|} 
M & Sherwood & 1 October 2014 \\
\hline N & Oxley & 9 October 2014 \\
\hline O & Graceville & 16 October 2014 \\
\hline P & Sherwood & 30 September 2014 \\
\hline
\end{tabular}

Source: authors.

The research also utilises secondary sources, especially submissions made to the QFCI, an investigative body set up by the Government of Queensland with a wide-ranging brief, and its Interim Report and Final Report (QFCI, 2011, 2012). As the Chair of the Commission, Honourable Chief Justice Catherine Holmes, clarified in the Preface to the Interim Report (QFCI, 2011, p. 5):

\footnotetext{
I am to inquire (in summary) into the preparation and planning for the flooding by governments at all levels, emergency services and the community; the supply of essential services during the floods; the adequacy of forecasts and early warning systems, with particular reference to Toowoomba and the Lockyer Valley; compliance with, and the suitability of, dam operational procedures for safety and flood mitigation; land use planning to minimise flood damages; and the performance of insurers in meeting their claims responsibilities.
}

The Interim Report (QFCI, 2011) dealt mainly with dam operational matters, warnings, and emergency responses, whereas the Final Report (QFCI, 2012) extended itself to land use planning and other issues. The inquiry received public submissions and sought expert advice. Its reports and the submissions made to it are matters of public record.

The qualitative case study nature of this research prohibits the generalisation of the results to the wider Brisbane community or to environmental disasters in general, but, nonetheless, it does provide some answers to the two research questions set out above, as well as evidence pertaining to the critical importance of risk communication and risk perception related to flood disasters. This evidence will be relevant to flood management response and recovery in other contexts. That some of the responses are contradictory also helps to emphasise the variety of experiences 
of flood victims and hence the assortment of communication and risk identification approaches that are necessary.

\section{The 2011 floods: risk communication, risk perception, and associated overlaps and gaps Risk communication}

State and local government engaged in the communication of risk information through warnings. Both told the QFCI of the ways in which they had issued information and warnings concerning the floods. The submission by the Government of Queensland's Department of Community Safety (as it was called in 2011) identified a range of possible ways that communities could be made aware of an impending emergency, including by the internet, radio and television, social media, telephone announcements (emergency alert), and verbally via door-knocking (State of Queensland, 2011, p. 1). It noted that some 37 separate warnings were disseminated in central and southeast Queensland between 26 December 2010 and 14 January 2011.

Brisbane City Council (BCC), in its initial submission to the inquiry, emphasised its official responsibilities in disaster planning and response, as set out in the Disaster Management Act 2003 (Queensland). In addition, it pointed to its flood database, the Floodwise Information System and a subscription-based Early Warning Alert System, both of which provided information and warnings regarding the 2011 floods (BCC, 2011, pp. 9-10).

The above shows that interventions occurred at the state and local government level to provide the residents of Brisbane with information on flood risks and to propagate various kinds of warnings about the impending 2011 floods in the days before the event itself.

Yet, the responses of the people who were interviewed for this research revealed considerable difference between the intentions of these public actions and their impact on the experiences of respondents. These were all people whose properties had been flooded. As the comments of Interviewees D and B in the next subsection show, public information on the long-term risk of flooding was not always felt to be reliable. As Interviewee $\mathrm{C}$ demonstrated, other people drew on other sources of risk information: 
Yep. [The house] had never been flooded. There was an old lady next door that had been there since 1940 and she said [...] (Interviewee C).

[The real-estate agent] said it had never flooded (Interviewee C).

\section{Risk perception}

Since floods can take many different forms, there are at least two areas where the perception of flood risk is important. The most commonly referred to is pre-disaster awareness of the possibility of flooding (using measures such as a 1-in-100 annual exceedance probability, or more colloquially, a 1-in-100-year flood). However, as the Australian Water Association (2011, p. 8) said in its submission to the QFCI: '[o]ne of the key failings of the public communication undertaken with the recent floods was the explanation of what potential flood heights meant. The community has little understanding of what a flood height at the City Gauge at Edward Street means in relation to possible flooding where they are located'. It identified a clear gap between communication based on professional knowledge and expertise (as often used by government agencies) and community understanding of that communication. A similar point was made by Grigg (2011a, p. 1), an expert hydraulic engineer, in his submission to the QFCI: '[t]he Brisbane River flooding in January 2011 has demonstrated, as was the case in 1974, that the community at large appears to have been poorly equipped to appreciate the extent of the flood hazard, to interpret flood warnings, to understand flood maps, and to have formulated flood evacuation strategies relevant to their property'.

Risk perception is tied to the information available to those assessing risk, as well as to how they interpret that information. There was considerable divergence among the study interviewees in relation to this point. Several had checked the available flood risk information or had historical knowledge of the area but still felt that their properties were safe. Frequently, there was clearly awareness of the flood risk situation, but this was followed by a calculated assessment of the potential risk outcomes in their specific location. Risk awareness appeared to be moderated by a filter of the potential benefits (not having to move possessions and find somewhere else to stay, for example) and costs (potential losses). Interviewees D and B reinforced these interpretations: 


\begin{abstract}
Yeah, we lived here for about a year before the floods. We bought this house and we checked out the flood information before we bought this house. Because my husband is a civil engineer and he checked the flood reports, he said it's OK, it would only come to the top of the driveway. So we thought there won't be any problem like the ' 74 floods (Interviewee D).
\end{abstract}

Right at the start, when we bought the house, we did look at the flood maps. A corner of our land was within the 100-year flood zone, which is [at] the eight-metres above sea-level [mark]. But we didn't think that the flood would reach our house. When we bought the house we didn't think it would actually be affected like it was (Interviewee B).

In other words, some of the residents to whom the researchers spoke, while not making fully calculated actuarial cost-benefit calculations, had assessed the risks, interpreted them in their own way, and made decisions based on that understanding. It is also clear that these respondents were unaware of the uncertainties inherent in modelling flood levels. The Brisbane flood maps, now called flood awareness maps by the city council (BCC, 2018), were based on the levels reached during the 1974 floods, modified by later hydraulic modelling and using a 1:100 annual exceedance probability. Such mapping is common across Australian local governments, and increasingly the mapping results are being made available on council websites. The 1:100 benchmark is widely employed in this modelling (Box et al., 2012). Modellers would be cognisant of the uncertainties inherent in defining these areas on a map, reflecting, inter alia, land development, local riverbed changes, shifting catchment characteristics, and varying rainfall patterns. The two users quoted above, though, seemed to expect an impossible degree of exactitude in the mapping.

The nature of the built environment in parts of Brisbane would also affect perceptions of risk. Many houses in the flood-affected areas were 'high set', or raised above ground level on stumps (see Figure 1). Flood maps are related to topography but not to built form. A common response to flood warnings, mentioned by several of the interviewees, was to move goods from the ground level (used mainly as a garage or for storage or services such as laundry) to upper floors, supposedly above the probable flood height. Living in a high set house could give a sense of security. Although this sometimes proved false, further raising the post-flood level of habitable floors was one of the flood responses available to some Brisbane residents and an option made more widely available by the city council after the 2011 floods. 
Figure 1. 'High set' house in Sherwood, Brisbane, raised after the 2011 floods

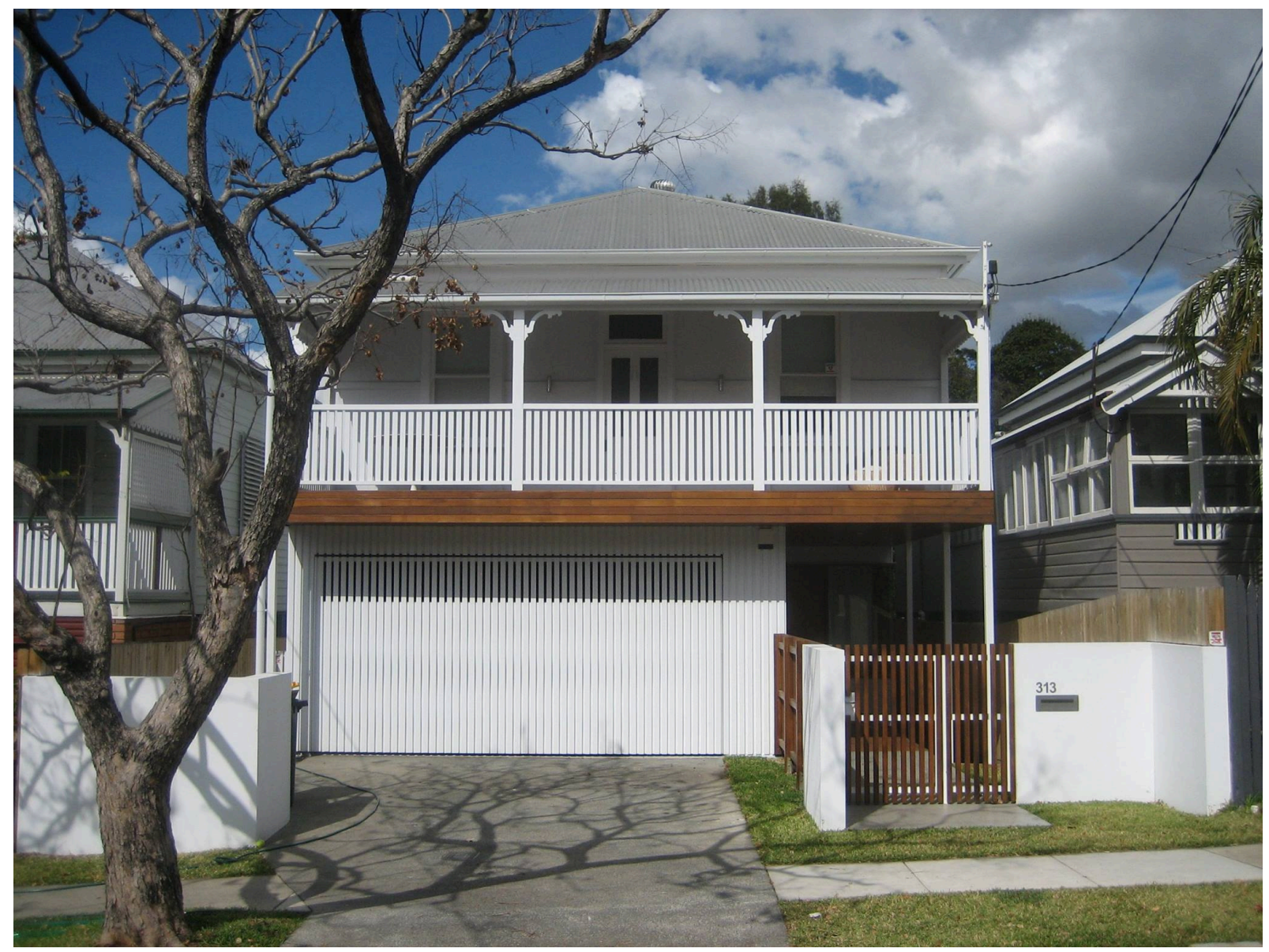

Source: authors.

The 2011 floods illustrated another facet of the perception of risk, that of opinions during the event itself. Residents needed to make important decisions, especially about whether or not to evacuate, and, if so, when to do it. The decision was influenced by views of how high they expected the then-visible floodwaters to rise. As the 2011 floods were caused by rain falling in the upper catchment of the Brisbane River and the river and floodplain topography, the water spread relatively slowly outwards once the river had penetrated its banks. In addition, by the time of the peak of the flood, rainfall in the city had ceased and the skies over Brisbane were clear and almost cloudless. Consequently, although there was an obvious flood situation, there was still room for confusion about what the direct impact would be in a particular location. This ties in 
with the reference of Perry (1979) and Mileti and Sorensen (1990) to the efficacy or otherwise of local weather conditions as a confirming mechanism for flood warnings. As two comments by Interviewee $\mathrm{C}$ illustrate, there was uncertainty about the probable future impact of the 2011 floods even as the water was rising:

And I remember there were some uni [university] students who had a set of picnic chairs on the road and as the water came up they were playing the game of who was going to move their feet last, do you know what I mean? And so there was this friendly banter, it was all very light and friendly (Interviewee C).

... so the water kind of came up and initially it was a novelty $[\ldots$ and $]$ we actually had quite a nice vantage point, it looked quite high. So we had this endless stream of people coming in for a beer (Interviewee C).

Disaster managers need to consider perceptions of risk both in the general sense of the overall probability of flooding and in terms of the direct impact at certain locations and at particular times. In the absence of a general command to evacuate (as in Brisbane), individual residents have to make their own decisions and obviously use what they can see in front of them to guide their determination. This situation resonates with a problem identified by Green, Tunstall, and Fordham (1991, p. 232): falsely assuming that 'people have a passive role in the decision-making process'. In the Brisbane flood context, they were unmistakably active decision-makers in matters that affected their safety and well-being:

So by the time we drove out down to the bottom of the street, there was actually about a foot of water over the street coming up, and we were just lucky to have made the right decision to get out. There were other people not doing anything, everybody just asking what will you do, how high do you think it is gonna be? (Interviewee D).

Perceptions of the degree of risk can also be influenced by experience, as identified by ElrickBarr et al. (2015) in their study of coastal communities. In some cases, this may lead to extra caution, but it can also result in complacency: 
I think I have always had a fairly clear idea that this was a flood zone. I knew all about flood risks, but in general, knowing all of the issues and being in a circumstance where you can make decisions [...] Even with knowledge you become complacent over the years. We have had a lot of small floods and you can deal with them, and we've become fairly complacent, it's just another small event. And the general community became complacent (Interviewee P).

Well I grew up in Graceville and I knew this was a swamp area down here. My father, if he had been alive, probably wouldn't have let us buy here (Interviewee L).

It was two things, because I knew it could flood before. But before the flood you think, if there is flood I would be fine, I would be able to cope with it. After you have been through one, you realise that what you have actually been through is not what you thought it was, it actually was a lot worse. So two things now I carry with me: one is I am more aware that there was a higher risk than I thought there was; the other thing is the experience of going through [a flood like this] is worse than you think (Interviewee K).

In at least two cases, the perception of the degree of risk faced by the property was reduced because of trust in the regulatory performance of the $\mathrm{BCC}$ as the land use and development regulatory body:

So nobody really had a clue and when we bought the property, these properties are nearly 12 years old, when this complex was built they put in a lot of fill and it was supposed to be above flood level. So on many of the flood maps this side was above the flood level, so we didn't expect to be flooded. Many of the reports suggested that it might come up to the garage but it wouldn't come further (Interviewee $\mathrm{O}$ ).

I was aware of flood risk prior to moving into my current property but this estate was not developed for several years after the 1974 flood and I was under the impression that the land was built up to be above the 1974 flood level (Interviewee F).

\section{Overlaps between risk communication and risk perception}

Two sets of observations reflect the specific context of Brisbane and its flood history, but nonetheless are significant for other situations. The first is the comparisons made with the 1974 floods, the highest to occur in Brisbane in the twentieth century. These comparisons seem to suggest a potential overlap between risk perception and risk communication. Some interviewees 
had lived through the earlier event, either in the same suburb or elsewhere, and used it as a basis for their judgements about the 2011 floods. Their experience helped to shape their perceptions of risk as well as how it affected them:

... well I grew up in 1974 after that flood, so I had a good idea of what flood risk was in the area, so you sort of all learn to grow, respecting the flood (Interviewee H).

Considering I had been through the '74 floods I thought I was a bit silly [for] not having checked that out a bit more carefully, but I escaped just (Interviewee E).

The second set of observations relating to information on flooding concerns the supposed, or anticipated, impact of the completion of the Wivenhoe Dam. The dam was finished in 1984 after the 1974 floods and was intended to serve at least a partial flood mitigation purpose (Grigg, 1977). Expectations of its flood mitigation role seem to have grown among Brisbane residents since the dam was completed; there was widespread belief that the dangers of flooding had been minimised, if not removed. Grigg (2011a, p. 2) makes it clear that the Somerset and Wivenhoe Dams could alleviate flooding, but that they could never control or stop it, and that this 'is still not well understood by large sections of the community'. Interviewees often mentioned their thinking, before the 2011 floods, that the construction of the Wivenhoe Dam would greatly reduce the overflow of water from the Brisbane River. Interestingly, though, this was usually in generic terms, such as 'people said ...' or 'there was talk that ...', although one claimed to have received this kind of information from official sources. The responses of interviewees included:

They said as soon as the Wivenhoe Dam was built there will be minor floods, but there won't be anything like the 1974 one and so forth (Interviewee P).

I was aware of the risk before, but I had a lot of faith in the risk mitigation measures the council put in, like the Wivenhoe Dam (Interviewee K).

... we bought this house in 1996 and were aware that it had flooded in 1974, but there was always a lot of talk of [the] Wivenhoe Dam being the magic fix and that it won't happen again. That's what people say (Interviewee J). 
We did understand that this house had been flooded in ' 74 when we bought it and that since '74 [the] Wivenhoe Dam was built (Interviewee M).

You know, [in] '74 that was one experience, you know. And then they built the dam and they said, 'we don't have any more floods', you know, because they dammed it off (Interviewee I).

There are implications here for other locations where flood mitigation infrastructure is in place. It is apparent that public expectations may need to be managed and misleading beliefs confronted. This is a clear example of what Domeneghetti et al. (2015, p. 809) call the 'levee effect', which leads to greater and more intense development on land where risks are thought to have been alleviated by protective infrastructure. Grigg (2011a, p. 2) underlines that 'experience around the world ... highlights that following the construction of engineering measures [such as the two dams, the] encroachment of additional activities onto the floodplain, in the absence of other complementary flood plain management measures, is almost inevitable'.

\section{Gaps between risk communication and risk perception}

There was a sizeable gap between the intentions of the official flood warnings and the responses in particular localities. Several factors were at play here, of which four are particularly important. One was contextual: the spatial extent of the Queensland flooding. The second was the scale of the $\mathrm{BCC}$ and hence the problem of providing warnings for specific localities. The third was the lack of understanding by at least some members of the community about the meaning of the warnings. The fourth was the potentially confusing disconnection between the apparent behaviour of the floodwaters and the potential danger posed by them.

The first factor is important because such a large area of Queensland was affected in December 2010 and January 2011. Queensland spans an area of 1,727,000 square kilometres, making it nearly seven times the size of the United Kingdom, or almost 2.5 times the size of Texas in the United States (Queensland Government, 2017). This meant that the state government's warning system, as well as its response and recovery effort, was spread across a huge area; in many different localities, the specific local impacts of the flooding would differ, therefore. Thus, there were generalised warnings from the Government of Australia's Bureau of Meteorology, which were localised within the limits of rainfall data collection and modelling, as well as warnings 
from the state government's emergency services. Telephone-based warnings were issued across affected parts of Queensland from mid-December and disaster declarations from late December (State of Queensland, 2011, p. 23).

The complexity of coordination of the warning system among state government departments, government-owned enterprises, and local governments involved in disaster management (and hence communication of warnings) is illustrated by the fact that, although meetings had started in October 2010 to develop a 'flooding information communication protocol', it had not been finalised by the flood peak in early January 2011 (State of Queensland, 2011, p. 20).

Similarly, scale (the second factor) is important in Brisbane. The BCC is responsible for the largest population of any local government in Australia (some 1,142,000 people in 2011) (Australian Bureau of Statistics, 2013) and territory that spans some 1,670 square kilometres. It covers the largest area of any fully urban local authority in the country, adding to the difficulties faced by the council in dealing with the 2011 floods. The BCC $(2011$, p. 2) noted in its submission to the QFCI that '[o]n 11 January 2011, the Local Disaster Coordination Centre activation was increased and the Lord Mayor issued a media release warning of a major flood event and urged residents to prepare for it'. This was two days before the flood peaked. At least some of the study interviewees were uncertain about the implications of these warnings for their particular locality. In one case the respondent's husband had been told by his employer to go home and prepare (as it had said to all of its staff), but the household still had difficulty in assessing the level of threat to its house:

So he came home with sort of checking things but it was really hard to tell what to do, because I don't really know what the given numbers about metres means (Interviewee D).

The same respondent knew of letterboxing by the council, but the woman did not think this was important — she attached more weight to radio, television, and the advice of neighbours:

You can see the councillor walk around and put letters in the letterbox, but I just ignored it. Obviously, there was stuff on TV and radio. I trust my neighbour, because they have been here for a long time, even during the ' 74 flood. I really trust what they said (Interviewee D). 
The third and fourth factors are related: the conceptual gap between the warnings and peoples' understanding of them, and the experiential gap presented by the floodwaters and their slow rise compounded by the sunny weather, together created ambiguity in some respondents' minds about the degree to which one should heed the warnings. One respondent even called the flood 'benevolent', trying to contrast the violence and intensity of a bushfire with the perceived gentle, slow progressive rising of the riverine flood:

It never flowed strongly. It was all very quiet. At any particular time a flood is benevolent. It's not like a fire where at a time it is fierce and intense and threatening; a flood is just benevolent, and you'll see the lap, lap, of the water, you know what I mean? But it's just that it keeps coming (Interviewee C).

As mentioned, some interviewees described a party-like atmosphere as people sat on chairs and drank beer while the floodwater rose slowly in the park across the street from them; eventually, however, there was a realisation that the situation was becoming serious as the water kept coming, debris and waste started to flow along with it, or the streets became impassable. In the words of Interviewee C, they just:

\footnotetext{
look[ed] at the water, because you actually got a nice view. And nobody at that stage said 'I think you should get your stuff out'. Nobody mentioned it. ... There were warnings on the radio but there was nothing in the particular context of where we were at. So no one sounded a concern (Interviewee C).
}

This response demonstrates quite clearly the social character of risk perception. Individuals were influencing other individuals via their behaviour at the flood interface. This is despite official warnings being issued over the radio. Communications concerning the looming threat, as well as the impending danger presented by the flood, needed to be cognisant of this social characteristic of risk perception.

Interviewees often pointed to inadequate warning measures and confusion about the focus of the warnings. In part this was a result of the institutional fragmentation that becomes apparent during many disasters. As was expressed by a number of the respondents, there was an expectation that the $\mathrm{BCC}$ would provide flood warnings relevant to its particular locality. Yet, the state 
government was also involved, with the then Premier of Queensland, Anna Bligh, adopting a high profile in television coverage of the flood across the state, and the Government of Queensland's Department of Community Safety assuming legal responsibility for disaster management. Warnings based on rainfall and hydraulic modelling were provided by the Government of Australia's Bureau of Meteorology. There was no single authoritative source to which respondents could turn for up-to-date warnings relevant to their own locality.

The most significant issue for many was the immediate implications of the warnings for their locality. Clearly, general warnings are of some use, but warnings that are targeted at particular suburbs or areas have a great deal more significance:

We got warnings for several days, but we didn't get the warning that we were actually going to flood until the water was almost on top of us. Some people got caught but a lot of people are pretty wise around here, they packed up and got out (Interviewee F).

Some of the interviewees had been targeted in this way: police officers visited their houses and advised them to evacuate. This made households certain of the actions that were expected of them:

The full story is that we were told to evacuate by the police. They door-knocked. They actually came to our door and told us we had to evacuate. And we said, 'great, we'll do that later on in the day. So we have more time to prepare for the flood'. We weren't entirely convinced that we were going to get water in the house. So we decided, OK, we'll evacuate now (Interviewee B).

However, this public information, when provided, was not always so clear or satisfactory:

Yes, the council provided it, they were very cautious, you could go in and ring the council as well as see their websites, but they had prepared a statement in relation to each block, to say the flood level would reach 5.5 or 6 metres ... do you know what that means? They also said I can't explain it to you, you just have to read it, but it was completely wrong. It wasn't until very late that the extreme extra heights of the water appeared, very late, just in the last 12 hours before the major flood (Interviewee P). 
It is apparent from the various interview responses that there was indeed institutional fragmentation (or at least, perceptions of fragmentation or divergent expectations about sources) with regard to the communication of a flood warning.

Direct experience of flooding, or advice from others with such knowledge, was treated significantly differently from advice from official sources by some respondents. In this case, the experience and actions of those who had been through the 1974 floods were given appreciable weighting (although why their example was not followed remains puzzling):

All the old locals who had been there in the ' 74 floods were packing up and moving gear out. The newcomers were wandering around the street with a glass of wine or something, saying: 'I don't think it's going to be that serious, do you? I think we'll be alright'. Of course, they [the floodwaters] went under up to the ceilings just about (Interviewee E).

Communication also needs to be targeted at the circumstances of the recipient. As one older interviewee noted: 'I'm still a bit old school and watch TV rather than use computers like you young people do' (Interviewee J). With respect to disaster management, one should note that internet connections and radio and television signals later failed owing to power being cut off by the authorities to prevent electrocution. Many of the people interviewed referred to the loss of power and its consequences for communication.

\section{Conclusion}

This paper has drawn on the experience of households affected by the 2011 floods in Brisbane, Australia, to identify issues and lessons about risk perception and risk communication. It set out to answer two questions: what can the experiences of flood-affected community residents tell us about risk communication and risk perception?; and what lessons can research and policy on flood risk communication and risk perception draw from the experiences of Brisbane in 2011 ? The observations made here indicate where overlaps and gaps occurred that led to some problematic responses to the riverine disaster. In the case of overlaps, the forms of risk communication and the divergences in and the ambiguities of risk perception are seen to have created a situation where a false sense of security was present among interviewees vis-à-vis flood height and the characteristics of buildings, properties, and business premises. Gaps appeared 
where the warning information that was communicated differed from actual flood experience and related environmental cues. These lacunae underscore the need to integrate more deeply the organisational design of the warning system, the communication of the warning, and the warning information itself and the signals that it can produce, especially in terms of its relevance at specific localities. Particular aspects that were identified in the research findings included the context of the dwelling and residents' experiences, as well as the meaning and local relevance of warnings (cf. Perry, 1979; Mileti and Sorensen, 1990; Mileti and O’Brien, 1992; Dash and Gladwin, 2007; Elrick-Barr et al., 2015).

The data show that cultural and social circumstances influenced the way in which residents perceived flood risk. The effectiveness of the communication was compromised by a disconnection between the largely specialised and technical nature of the information given and how residents interpreted it — or failed to understand it—when making their decisions on how to respond. This led to unintended and problematic consequences, especially regarding the urgency of individual decision-making in relation to the degree of risk, which often was underestimated.

Inadequate warnings neither provided relevant and timely information on longer-term risk assessments (the probability of flooding occurring) nor the risks faced during the event itself. The resulting decisions made during the response phase influenced recovery afterwards. Generally, the householders interviewed made no clear distinctions among the phases of the unfolding disaster (prevention-preparation-response-recovery), at least partially because of the ambiguity of the threat posed by slow-onset riverine flooding. This indicates that individual decisions made during the response phase (which for floods such as those in Brisbane in 2011 extend back to the time when the waters were building up) need to be considered in the context of the entire disaster management cycle.

One particularly troubling observation is the gap between the complexity of communicating the warning information owing to the multiple tiers of government involved and their potentially overlapping responsibilities. There is a need for ongoing communication and confirmation as such flood events unfold. Since power outages compromised attempts to provide radio, television, and internet-based warnings, door-to-door warnings proved most effective. 
Interviewees were not able to retrieve relevant information from confirmation centres because of a lack of knowledge among those tasked with answering confirmation requests, hampering twoway communication. Residents did, in fact, play an active role in acquiring and interpreting information on warnings and risk. Here, awareness was based on choosing information sources in relation to cultural and social circumstances, experience, and self-protective behaviour. This activity, though, was also related to environmental cues that may be disconnected from the warning information.

Individuals had high expectancies about the modelling accuracy on which flood maps are based and so did not appear to take uncertainties involved in flood modelling into account. Interviewees felt informed, and yet they were surprised about the eventual actual impacts. One reason, as reported by those who experienced the 1974 floods, was that the 2011 floods were considered worse than the 1974 floods, even though the recorded water height was lower. There was pronounced uncertainty as to how the flooding would relate to a particular location, and hence the actual meaning of flood height information remained unclear. The particularities of each location in the city, in combination with existing flood map information, the presence of the flood mitigation dam, and whether houses were perceived as 'safe' owing to being high set, were not considered adequately. Given the topography, built form, and history of flooding in the researched neighbourhoods, the flood risk may have been high for some, while their immediate neighbours, as well as other households in the same street, might not have suffered flooding. Each of these factors had the potential to confuse official warning communications, leading to uncertainty and feelings of false security, at least among some of the study respondents. Whether or not this confusion was widespread is a matter for further research; however, the findings do point to a need for more targeted warnings and a possible need to rethink the conceptual basis on which they are issued.

The example of the Wivenhoe Dam emphasises the importance of social factors - it is less its technological performance and more the way in which the public interprets its mitigatory capacity that informs residents' views of flood risk. Notions of false security through a 'levee effect' can be traced to the construction of the Wivenhoe Dam and its intended mitigatory purpose. In the case of Brisbane, and for some of the respondents, the 'levee effect' was real. In 
addition, the overlapping of functions with respect to the Wivenhoe Dam raises serious concerns about the aims of resilience-oriented planning projects that seek to integrate recreational, infrastructural, and mitigatory functions within one structure.

In sum, there was (i) a lack of community understanding of the risk because of the way it was expressed, usually as potential heights above a certain river gauge, and (ii) people were still uncertain about how the flood would affect their house in their particular location. The observations made add further detail to available official documentation (cf. Australian Water Association, 2011; Grigg, 2011a, 2011b; Insurance Council of Australia, 2011; QFCI, 2011, 2012).

The research findings point up some challenges to the warning system design, the communication and perception of risk, and the relevance of environmental aspects, leading to the following recommendations:

- Focus institutional responsibilities. To promote improved understanding of risk warning information, related institutional responsibilities need to be coordinated more clearly. A warning system can then work better to communicate the information on risk that residents need for them to be able to respond adequately. Institutional fragmentation should be addressed and adjusted accordingly in terms of who provides which warnings and for whom (cf. Mileti and Sorensen, 1990; Kim and Oh, 2015). A single, central, local source is most effective, but it should be able to communicate specific and locally useful information on risk, not just general information applicable to a wide area.

- Provide targeted information. To relate better to the scale of the area affected by a disaster, the warning system should reflect the difference in scale from the city to the neighbourhood/suburb level. Personal, door-to-door communication is most effective, as the research findings confirm, yet it can bind scarce resources. The confirmation mechanism needs to communicate precise information to those seeking substantiation (cf. Perry, 1979; Mileti and O'Brien, 1992). This highlights the importance of a community or neighbourhood-based approach in combination with technological innovation, such as social media. 
- Promote the active roles of residents. To support understanding and personalisation of warning information, the active roles of residents and effective two-way communication between them and officials are important (cf. Rodriguez et al., 2007; Twigg, 2013). This can reinforce the necessary communication of targeted information in relation to specific at-risk locations, including communications and warnings issued during ongoing flood events, pre-flood alerts, and recovery-related information. Improved city-citizen cooperation (cf. Wamsler, 2016) appears to be key.

- Avoid misinterpretation based on environmental cues. Deeper integration of flood risk information and local site information should be considered. If room for interpretation is too large, misinterpretations and undesirable consequences may be the result. Environmental cues play an important role, and risk may differ from one street to the next based, for example, on flood elevation and built environmental conditions (cf. Dash and Gladwin, 2007; Domeneghetti et al., 2015). High set houses, protective structures, or overconfidence in the accuracy of flood maps may contribute to a false sense of security. Such notions need to be challenged to incentivise compliance with warnings and an adequate response.

Disaster management planners need to be aware of these circumstances to avoid gaps between stated intentions and actual outcomes that limit or reduce the ability of residents to respond. This applies to risk communication before and during flood events. Communicating professional knowledge in a way that supports community needs can help to avoid misinterpretation of risk information by residents who can play active parts in dealing with risks.

While some of the observed deficits can be related to the overwhelmingly strong impact of the 2011 floods in Queensland, the research findings presented here may very well be useful in improving risk perception and communication among institutions and residents at risk in other contexts. As a result, the potentially negative and undesirable consequences of inadequate risk communication and divergent risk perceptions can be avoided, supporting targeted response and recovery.

\section{Acknowledgments}


The authors would like to thank the School of Earth and Environmental Sciences at the University of Queensland and the individuals who participated in the research.

\section{Correspondence}

Dr Mark Kammerbauer, Augsburg University of Applied Sciences, An der Hochschule 1, 86161 Augsburg, Germany. E-mail: Mark.Kammerbauer@HS-Augsburg.de

\section{References}

Australian Bureau of Statistics (2013) Socio-Economic Indexes for Areas (SEIFA). Technical Paper. 2033.0.55.001. Australian Bureau of Statistics, Canberra. http://www.abs.gov.au/AUSSTATS/abs@.nsf/DetailsPage/2033.0.55.0012011?OpenDoc ument (last accessed on 16 August 2018).

Australian Government, Bureau of Meteorology (2011) 'Flood summary for Brisbane River at Brisbane - December 2010 and January 2011'. Australian Government, Bureau of Meteorology Melbourne. http://www.bom.gov.au/qld/flood/fld_reports/brisbane_fact_sheet_2011.pdf (last accessed on 16 August 2018).

Australian Government, Bureau of Meteorology (2017) 'Known floods in the Brisbane and Bremer River Basin - including the cities of Brisbane and Ipswich'. Australian Government, Bureau of Meteorology, Melbourne, Australia. http://www.bom.gov.au/qld/flood/fld_history/brisbane_history.shtml (last accessed on 16 August 2018).

Australian Water Association (2011) Submission to the Queensland Floods Commission of Inquiry, 4 April 2011.

http://www.floodcommission.qld.gov.au/_data/assets/file/0019/6148/Australian_Water_ Association.PDF (last accessed on 16 August 2018).

BCC (Brisbane City Council) (2011) Queensland Floods Commission of Inquiry, Initial Submission, 11 March 2011. http://www.floodcommission.qld.gov.au/_data/assets/file/0020/8363/BCC_Brisbane_C ity_Council_11.03.11.pdf(last accessed on 16 August 2018). 
BCC (2018) 'Flood awareness map'. 21 May. https://www.brisbane.qld.gov.au/communitysafety/community-safety/disasters-emergencies/be-prepared/flooding-brisbane/floodawareness-maps (last accessed on 16 August 2018).

Box, P., F. Thomalla, R. van den Honert, and J. McAneney (2012) 'How can residents know their flood risk: a review of online flood information availability in Australia'. Australian Planner. 49(4). pp. 339-348.

Bubek, P., W.J.W. Botzen, and J.C.J.H. Aerts (2012) 'A review of risk perceptions and other factors that influence flood mitigation behaviour'. Risk Analysis. 32(9). pp. 1481-1495.

Burningham, K., J. Fielding, and D. Thrush (2008) “'It'll never happen to me”: understanding public awareness of local flood risk'. Disasters. 32(2). pp. 216-238.

Dash, N. and H. Gladwin (2007) 'Evacuation decision making and behavioral responses: individual and household'. Natural Hazards Review. 8(3). pp. 69-77.

Demeritt, D. and S. Nobert (2014) 'Models of best practice in flood risk communication and management'. Environmental Hazards. 13(4). pp. 313-328.

Domeneghetti, A., F. Carisi, A. Castellarin, and A. Brath (2015) 'Evolution of flood risk over large areas: quantitative assessment for the Po River'. Journal of Hydrology. 527 (August). pp. 809-823.

Douglas, M. and A. Wildavsky (1982) Risk and Culture: An Essay on the Selection of Technological and Environmental Dangers. University of California Press, Berkeley, CA.

Drabek, T.E. (2005) 'Predicting disaster response effectiveness'. International Journal of Mass Emergencies and Disasters. 23(1). pp. 49-72.

Elrick-Barr, C.E., T.F. Smith, D.C. Thomsen, and B.L. Preston (2015) 'Perceptions of risk among households in two Australian coastal communities'. Geographical Research. 53(2). pp. 145-159.

Emergency Management Australia (2004) Emergency Management in Australia: Concepts and Principles. Australian Emergency Manual Series. Manual Number 1. Attorney General's Department, Canberra.

Godber, A. (2005a) Urban Floodplain Land-use - Acceptable Risk? A Case Study of Flood Risk Perception on the Guragunbah (Carrara-Merrimac) Floodplain, Gold Coast. 
Unpublished PhD thesis. School of Humanities and Social Services, Queensland University of Technology, Brisbane.

Godber, A. (2005b) 'Urban floodplain land-use: acceptable risk?'. Australian Journal of Emergency Management. 20(3). pp. 22-26.

Green, C.H., S.M. Tunstall, and M.H. Fordham (1991) 'The risks from flooding: which risks and whose perception?'. Disasters. 15(3). pp. 227-236.

Grigg, T. (1977) A Comprehensive Evaluation of the Proposed Wivenhoe Dam on the Brisbane River: A report Prepared for the Co-ordinator General's Department. Co-ordinator General's Department, Government of Queensland, Brisbane.

Grigg, T. (2011a) 'Muddy waters: the reality of Brisbane River flooding - submission to the Queensland Floods Commission of Inquiry'. http://www.floodcommission.qld.gov.au/_data/assets/file/0007/8368/Grigg_Trevor.pdf (last accessed on 16 August 2018).

Grigg, T. (2011b) 'Mitigating flood hazard: lessons learned and lessons ignored - the Brisbane River experience'. Queensland Planner. 51(1). pp. 18-20.

Henrich, L., J. McClure, and M. Crozier (2015) 'Effects of risk framing on earthquake risk perception: life-time frequencies enhance recognition of the risk'. International Journal of Disaster Risk Reduction. 13 (September). pp. 145-150.

Insurance Council of Australia (2011) Flooding in the Brisbane River Catchment, January 2011, Volume 1: An Overview. ICA Hydrology Panel, ICA, 20 February 2011. http://www.insurancecouncil.com.au/assets/report/volume\%201\%20\%20brisbane\%20valley\%20hydrology\%20\%28overview\%29.pdf (last accessed on 16 August 2018).

Kellens, W., T. Terpstra, and P. De Maeyer (2013) 'Perception and communication of flood risks: a systematic review of empirical research'. Risk Analysis. 33(1). pp. 24-49.

Kim, J. and S.S. Oh (2015) 'Confidence, knowledge, and compliance with emergency evacuation'. Journal of Risk Research. 18(1). pp. 111-126.

Lindell, M.K. and R.W. Perry (2012) 'The protective action decision model: theoretical modifications and additional evidence'. Risk Analysis. 32(4). pp. 616-632. 
Mackellar, D. (1908) 'My country'.

http://www.dorotheamackellar.com.au/archive/mycountry.htm (last accessed on 16 August 2018).

Mileti, D.S. and J.H. Sorensen (1990) Communication of Emergency Public Warnings: A Social Science Perspective and State-of-the-Art Assessment. Colorado State University for the Federal Emergency Management Agency, Washington, DC.

Mileti, D.S. and L. Peek (2000) 'The social psychology of public response to warnings of a nuclear power plant accident'. Journal of Hazardous Materials. 75(2-3). pp. 181-194.

Mileti, D.S. and P.W. O’Brien (1992) 'Warnings during disaster: normalizing communicated risk'. Social Problems. 39(1). pp. 40-57.

Perry, R.W. (1979) 'Incentives for evacuation in natural disaster research based community disaster planning'. Journal of the American Planning Association. 45(4). pp. 440-447.

QFCI (Queensland Floods Commission of Inquiry) (2011) Interim Report. August. QFCI, Brisbane.

QFCI (2012) Final Report. March. QFCI, Brisbane.

Queensland Government (2017) 'Interesting facts about Queensland'. December. https://www.qld.gov.au/about/about-queensland/statistics-facts/facts/ (last accessed on 16 August 2018).

Rahm, D. and C. Reddick (2011) 'US city managers' perceptions of disaster risks: consequences for urban emergency management'. Journal of Contingencies and Crisis Management. 19(3). pp. 136-146.

Rodriguez, H., W. Diaz, J. Santos, and B. Aguirre (2007) 'Communicating risk and uncertainty: science, technology, and disasters at the crossroads'. In H. Rodriguez, E. Quarantelli, and R. Dynes (eds.) Handbook of Disaster Research. Handbooks of Sociology and Social Research Series. Springer, New York, NY. pp. 476-488.

Seqwater (2015a) 'Somerset Dam'. http://seqwater.com.au/water-supply/damoperations/somerset-dam (last accessed on 16 August 2018).

Seqwater (2015b) 'Wivenhoe Dam'. http://seqwater.com.au/water-supply/damoperations/wivenhoe-dam (last accessed on 16 August 2018).

Shepherd, J. and K. van Vuuren (2014) 'The Brisbane flood: CALD gatekeepers' risk communication role'. Disaster Prevention and Management. 23(4). pp. 469-483. 
State of Queensland (2011) Submission for State of Queensland, 11 March 2011. http://www.floodcommission.qld.gov.au/submissions/view-submissions-a-to-z/viewsubmissions-a-to-z_result_1666_result_page=S.html (last accessed on 16 August 2018).

Twigg, J. (2013) 'Risk perception, public education and disaster risk management'. In H. Joffe, T. Rossetto, and J. Adams (eds.) Cities at Risk: Living with Perils in the 21st Century. Advances in Natural and Technological Hazards Research Series. Volume 33. Springer B.V., Haarlem. pp. 171-182.

van den Honert, R.C. and J. McAneney (2011) 'The 2011 Brisbane floods: causes, impacts and implications'. Water. 3(4). pp. 1149-1173.

Wamsler, C. (2016) 'From risk governance to city-citizen collaboration: capitalizing on individual adaptation to climate change'. Environmental Policy and Governance. 26(3). pp. 184-204.

Wardman, J.K. (2008) 'The constitution of risk communication in advanced liberal societies'. Risk Analysis. 28(6). pp. 1619-1637.

Wildavsky, A. and K. Dake (1990) 'Theories of risk perception: who fears what and why?' Daedalus, 119(4) (Fall), pp. 41-60.

Wption: who fears what and why?'. Daedalus. 119(4). pp. 41-60. 